\title{
A NOTE FROM THE AUTHOR
}

\section{Change of publisher}

Publication of all four volumes of Burmese: An Introduction, first published in 1994, has been transferred to the Northern Illinois University Press and the books are now re-issued with minor revisions.

\section{Change of audio format}

At the time of initial publication, the audio component of Burmese: An Introduction was issued on cassette tapes. Now that digital recordings are more widely used than tapes, the audio material has been converted to digital. Two advantages of this change are, first, that digital files are less bulky to store and transport than cassette tapes and, second, that it is far easier to find a particular section in the audio.

Neither the printed text nor the audio files have been changed to reflect the transfer from tape to digital. So when you read or hear a reference to a particular tape, please understand it as referring to the corresponding track in the audio files.

\section{Changes in Burma since the publication of this course}

Sixteen years have passed since the first publication of this course. During that time several aspects of life in Burma have changed.

First and most obvious are price levels:

- A cup of tea that cost K4 in 1993 now costs K150, and costs may well rise further. So, when practicing prices in the exercises, bear in mind that most prices need to be multiplied by 30 or 40 to correspond with the cost of living today.

Second, some institutions that appear in the course have been renamed, relocated, or discontinued. For example:

- Tourist Burma has been renamed Myanmar Travel and Tours.

- The National Museum has moved from Pansodan to Pyay Road.

- The Diplomatic Store is no longer operating.

If you search in Burma for places mentioned in the course, remember that they may no longer be there.

Third, digital cameras have largely replaced film cameras, and most telephones now have keys to press rather than dials to turn. References in the Lessons to film and dialing should be understood as reflecting technology at the time of writing.

Apart from such obvious physical changes in the life of the country, the language of the course is still the language that you will hear and read in Burma today.

\section{Errata lists}

While using the course over the years, teachers, colleagues, and students have helpfully pointed out some errors and inconsistencies in the text. These have been listed and are to be found, with their corrections, on a page at the end of each volume. 
